\title{
O042. Phase-dependent defective functional activity of the default mode network and facilitated temporal processing of nociceptive stimuli in cluster headache
}

\author{
Armando Perrotta ${ }^{1 *}$, Maria Grazia Anastasio ${ }^{1,2}$, Luigi Pavone ${ }^{1}$, Antonio Ferretti ${ }^{3}$, Piero Chiacchiaretta ${ }^{3}$, \\ Giovanni Grillea', Marcello Bartolo', Emanuele Siravo', Gianluca Coppola², Anna Ambrosini ${ }^{1}$, Roberto De Icco ${ }^{4}$, \\ Giorgio Sandrini ${ }^{4}$, Francesco Pierelli ${ }^{2}$
}

From Abstracts from the 1st Joint ANIRCEF-SISC Congress

Rome, Italy. 29-31 October 2015

\section{Background}

In cluster headache $(\mathrm{CH})$ during the active period we described a facilitated temporal summation (TS) of nociceptive signals at spinal level linked to a defective suprapinal control of pain and followed by a normalization of the values during the remission period [1]. TS of sensory neuronal responses to nociceptive stimuli is a form of central plasticity that shifts the sensory information from tactile to nociceptive before transmitting the nociceptive information to brain areas mediating pain sensation. This feature of the sensory system results pivotal in physiological nociception, for discrimination between innocuous and potentially dangerous stimulation, as well as in pathological nociception, for induction and maintenance of the central sensitization, subsequently resulting in pain chronification [2]. In this study we sought to determine which brain sites are involved in the modulation of temporal processing of pain sensation in $\mathrm{CH}$ subjects during both the active and remission period. We utilized functional magnetic resonance imaging (fMRI) to compare the Blood Oxygenation Level Dependent (BOLD) signal changes related to the temporal summation threshold (TST) of the nociceptive withdrawal reflex (NWR). We used the single NWR response as control stimulus.

\section{Methods}

We studied 10 episodic $\mathrm{CH}$ patients during both active and remission period and 17 healthy subjects (HS). Two

\footnotetext{
* Correspondence: arm.perrotta@gmail.com

${ }^{1}$ IRCCS INM Neuromed, Pozzilli, Italy

Full list of author information is available at the end of the article
}

types of stimulation blocks were delivered during the fMRI scanning according to the stimulation paradigms previously determined to evoke both the TST of the NWR (SUMM) and the NWR single response (SING).

\section{Results}

The analysis of the hemodynamic signals showed a comparable activation of sensory and pain related areas in both $\mathrm{CH}$ (during active and remission period) and HS. The most relevant differences emerged in the deactivation of both posterior cingulate cortex (PCC) and bilateral angular gyrus (AG) and in the activation of the anterior cingulate cortex (ACC). $\mathrm{CH}$ during the active phase showed a lack of deactivation of PCC and AG and a more relevant activation of the $\mathrm{ACC}$ when compared to $\mathrm{CH}$ during the remission phase and HS.

\section{Conclusions}

PCC, AG and ACC are considered to be pivotal in default mode network (DMN), with a high activity correlated to the rest and reactive deactivation during most tasks where the attention is directed externally. Our data have demonstrated that in $\mathrm{CH}$ during the active phase of the disease, the facilitation in temporal processing of nociceptive stimuli is linked to a defective functioning of the DMN. Interestingly, both these abnormalities are dependent on the clinical activity of the disease.

Written informed consent to publication was obtained from the patient(s). 


\section{Authors' details}

${ }^{1}$ IRCCS INM Neuromed, Pozzilli, Italy. ${ }^{2}$ Department of Medical and Surgical Sciences and Biotechnologies, "Sapienza" University of Rome Polo Pontino, Rome, Italy. ${ }^{3}$ Department of Neuroscience, Imaging and Clinical Sciences, University "G. d'Annunzio", Institute for Advanced Biomedical Technologies (ITAB), Chieti, Italy. ${ }^{4}$ IRCCS Neurological National Institute C. Mondino, Pavia, Italy.

Published: 28 September 2015

\section{References}

1. Perrotta A, Serrao M, Ambrosini A, Bolla M, Coppola G, Sandrini G, Pierelli F: Facilitated temporal processing of pain and defective supraspinal control of pain in cluster headache. Pain 2013, 154(8):1325-32.

2. Perrotta A, Serrao M, Sandrini G, Burstein R, Sances G, Rossi P, Bartolo M, Pierelli F, Nappi G: Sensitisation of spinal cord pain processing in medication overuse headache involves supraspinal pain control. Cephalalgia 2010, 30(3):272-84.

doi:10.1186/1129-2377-16-S1-A90

Cite this article as: Perrotta et al:: 0042. Phase-dependent defective functional activity of the default mode network and facilitated temporal processing of nociceptive stimuli in cluster headache. The Journal of Headache and Pain 2015 16(Suppl 1):A90.

\section{Submit your manuscript to a SpringerOpen ${ }^{\mathcal{O}}$ journal and benefit from:}

- Convenient online submission

- Rigorous peer review

- Immediate publication on acceptance

- Open access: articles freely available online

- High visibility within the field

- Retaining the copyright to your article

Submit your next manuscript at $\gg$ springeropen.com 